\title{
Cardiorespiratory Physiotherapy, Critical Care and Rehabilitation (CPCR) journal: a new source of scientific knowledge for physiotherapy clinicians and researchers
}

\author{
Marlus Karsten ${ }^{1}$ (D); Fabio Pitta ${ }^{1}$ (D); Rafael Mesquita ${ }^{1}$ (1)
}

\section{How to cite}

Karsten M, Pitta F, Mesquita R. Cardiorespiratory Physiotherapy, Critical Care and Rehabilitation (CPCR) journal: a new source of scientific knowledge for physiotherapy clinicians and researchers. Cardiorespir Physiother Crit Care Rehabil. 2021;1:e0001. https://doi.org/10.4322/2675-9977.cpcr.202101

Despite being a young profession, physiotherapy has established its role in most developed countries worldwide. The increasing number of randomised clinical trials and systematic reviews testing the impact of different physiotherapy interventions supports much of this achievement. This large volume of publications is exemplified in the Physiotherapy Evidence Database (PEDro), which has indexed more than 48,500 trials, reviews and evaluation guidelines for physiotherapy interventions by September $2020^{1}$. This provides strong grounds to put evidence-based physiotherapy into practice. The use of scientific knowledge has contributed largely to the advance of physiotherapy, both showing the effectiveness of novel and classic practices, as well as suggesting that certain procedures do not contribute to or even harm the patients' physical or functional condition.

The most used sources for putting evidence-based physiotherapy into practice are scientific journals. Notwithstanding, not many physiotherapy journals are currently available. In a search for journals clearly focusing on physiotherapy matters (i.e., those with physiotherapy/physical therapy in the name) and which have impact factor (possibly the most used metric to show the importance of a journal within its field), just about 10 journals are found ${ }^{2}$. Amongst these, five aim to publish manuscripts from various physiotherapy specialities and five focus on one specific speciality, but none of the latter focus on cardiorespiratory physiotherapy or physiotherapy in critical care. Researchers from these fields often publish in journals related to cardiac, respiratory and/or critical conditions, but not directly linked to physiotherapy. Therefore, a journal that receives and publicises research related to cardiorespiratory physiotherapy, rehabilitation and/or physiotherapy in critical care is of great importance to clinicians and researchers.

To fill this gap, Cardiorespiratory Physiotherapy, Critical Care and Rehabilitation (CPCR) was launched ${ }^{3}$. The main aim of CPCR is to publish scientifically rigorous research that can potentially contribute to the worldwide advance of cardiorespiratory physiotherapy, rehabilitation and/or physiotherapy in critical care in adults, elderly, paediatrics and neonates. CPCR vision is to be a reliable and recognised international source of knowledge for clinicians and researchers working with patients who present with cardiovascular and/or respiratory problems, as well as with critically ill patients.

CPCR is an official journal of the Brazilian Association of Cardiorespiratory Physiotherapy and Physiotherapy in Critical Care (ASSOBRAFIR), which is a well-established physiotherapy association in Brazil, with influence and

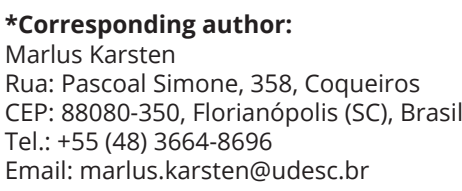


institutional partnerships outside its country ${ }^{4}$. Since the 1980s, ASSOBRAFIR is responsible for organising the International Symposium on Cardiorespiratory Physiotherapy and Physiotherapy in Critical Care (SIFR), possibly the world largest congress of cardiorespiratory physiotherapy, rehabilitation and physiotherapy in critical care, with about 2,000 attendants and 100 speakers. Furthermore, since the 1990s ASSOBRAFIR officially grants specialist titles (Respiratory Physiotherapist, Physiotherapist in Critical Care and Cardiovascular Physiotherapist) to Brazilian physiotherapists. In the last 10 years, ASSOBRAFIR has published a scientific journal (i.e., ASSOBRAFIR Ciência), which publishes articles mostly in Portuguese, serving the Portuguese-speaking physiotherapy community ${ }^{5}$. Differently, CPCR was born with the aim of attending and reaching a broad international community. CPCR has brought together a diverse group of editors and reviewers from different parts of the world in order to bring an international perspective on the research published.

It is also important to highlight some relevant characteristics of this new journal. CPCR adopts a double-blind peer review process, no charges for manuscript submission or publication, open access to all accepted manuscripts and a continuous publication model (meaning that articles become available online soon after they are accepted, with no paper publication and no need to wait until full volumes/numbers are completed). Moreover, CPCR aims to be a global physiotherapy journal mainly dedicated to specialities that frequently work together and have evolved considerably throughout the years. Notwithstanding, articles from other closely related fields are also welcome (e.g., sleep-disordered breathing, exercise physiology and training, public health, geriatrics, amongst others), as long as they present a clear link with the fields of cardiorespiratory physiotherapy, critical care and/or rehabilitation. More information about CPCR can be found in our website (https://cpcrjournal.org).
Finally, we would like to invite you to contribute to CPCR by submitting your manuscript and/or by serving as a reviewer, collaborating to the improvement of cardiorespiratory physiotherapy and rehabilitation, as well as physiotherapy in critical care. In this way, we will also cooperate with the evidence-based physiotherapy and, in the end, contribute to the improvement of costumers and patients care.

Marlus Karsten, $\mathrm{PhD}$

Fabio Pitta, PhD

Rafael Mesquita, $\mathrm{PhD}$

Editors-in-chief of the CPCR Journal

\section{References}

1. The University of Sydney. The Physiotherapy Evidence Database (PEDro) [Internet]. Sydney: Neuroscience Research Australia (NeuRA); 2020 [cited 2020 Oct 18]. Available from: https://pedro. org.au/

2. Analytics C. Journal Citation Reports ${ }^{\mathrm{TM}}$ (JCR) [Internet]. 2020 [cited 2020 Oct 18]. Available from: jcr.clarivate.com/

3. ASSOBRAFIR: Associação Brasileira de Fisioterapia Cardiorrespiratória e Fisioterapia em Terapia Intensiva. CPCR: Cardiorespiratory Physiotherapy, Critical Care and Rehabilitation [Internet]. São Paulo: ASSOBRAFIR; 2020 [cited 2020 Oct 18]. Available from: https://cpcrjournal.org/.

4. ASSOBRAFIR: Associação Brasileira de Fisioterapia Cardiorrespiratória e Fisioterapia em Terapia Intensiva. A ASSOBRAFIR e o desenvolvimento científico da especialidade [Internet]. São Paulo: ASSOBRAFIR; 2020 [cited 2020 Oct 18]. Available from: https://assobrafir.com.br/

5. ASSOBRAFIR: Associação Brasileira de Fisioterapia Cardiorrespiratória e Fisioterapia em Terapia Intensiva. ASSOBRAFIR Ciência [Internet]. São Paulo: ASSOBRAFIR; 2020 [cited 2020 Oct 18]. Available from: https://assobrafirciencia.org/. 


\section{Author contributions:}

MK, FP and RM contributed for the conceptualization and writing of the manuscript, as well as for revising it.

\section{Author information:}

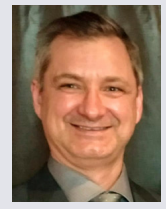

\section{Marlus Karsten, PhD}

Graduated in Physiotherapy, Universidade Estadual de Londrina, Brazil. PhD in Physiotherapy, Universidade Federal de São Carlos, Brazil.

Associate Professor, Department of Physiotherapy, Universidade do Estado de Santa Catarina, Brazil.

Scientific Director of the Brazilian Association of Cardiorespiratory Physiotherapy and Physiotherapy in Critical Care, Brazil.

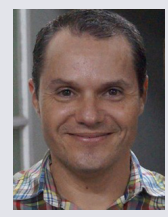

\section{Fabio Pitta, PhD}

Graduated in Physiotherapy, Universidade Estadual de Londrina, Brazil. PhD in Rehabilitation Sciences and Physiotherapy, Katholieke Universiteit Leuven, Belgium

Associate Professor, Department of Physiotherapy, Universidade Estadual de Londrina, Brazil

Researcher recipient of a productivity grant 1-D by the Brazilian Federal Government (CNPq, Brazil)

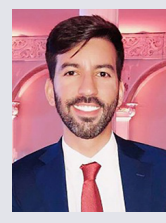

\section{Rafael Mesquita, PhD}

Graduated in Physiotherapy, Universidade de Fortaleza, Brazil.

PhD, Faculty of Health, Medicine and Life Sciences, Maastricht University, the Netherlands.

Adjunct-A Professor, Department of Physiotherapy, Universidade Federal do Ceará, Brazil

American Thoracic Society Pulmonary Rehabilitation Assembly: Web Committee. 